\title{
Cicadas "dig wells" that are used by ants, wasps and beetles
}

\author{
KAZUO YAMAZAKI \\ Osaka City Institute of Public Health and Environmental Sciences, 8-34 Tojo-cho, Tennoji-ku, Osaka 543-0026, Japan; \\ e-mail: kazuo-yamazaki@city.osaka.lg.jp
}

Key words. Cicada-ant interactions, commensalism, kleptoparasitism, sap feeders, xylem fluid

\begin{abstract}
There is a high density of the cicada Cryptotympana facialis (Walker) (Hemiptera: Cicadidae) in urban parks in central Japan during summer. This cicada uses its stylet to pierce holes in the trunks of keyaki trees, Zelkova serrata and then feeds on the exuding xylem sap. Three ant species, Formica japonica Motschulsky, Lasius japonicus Santschi and Crematogaster matsumurai Forel (Hymenoptera: Formicidae) were observed aggregatively feeding on these exudates. In addition, two wasp species, Polistes jokohamae Radoszkowski (Hymenoptera: Vespidae), and Ampulex dissector (Thunberg) (Hymenoptera: Sphecidae) fed on the sap. These ants and wasps can therefore be classified as commensals. Two flower chafers, Protaetia brevitarsis (Lewis) and P. orientalis submarumorea (Burmeister) (Coleoptera: Scarabaeidae) were also observed displacing cicadas from their feeding sites and feeding on the exuding sap. Thus, these chafers can be classified as both commensals and kleptoparasites.
\end{abstract}

\section{INTRODUCTION}

Hemiptera use their stylets to feed on plant sap inaccessible to most other insects. In particular, aphids and scale insects (Sternorrhyncha) feed on nutritious phloem sap and excrete the excess sugars as honeydew (Tjallingii \& Hogen Esch, 1993; Dixon, 2005). Ants and many other insects use honeydew as a food source, and many studies have examined the interactions between these Hemiptera and other insects, especially ants (e.g., Stadler \& Dixon, 2005). However, studies have rarely reported interactions between Auchenorrhyncha, other than treehoppers, and other insects (Delabie, 2001).

Cicadas, which belong to the Auchenorrhyncha, feed on xylem sap (Chueng \& Marshall, 1973; White \& Strehl, 1978; Williams \& Simon, 1995) and because several species of cicada often become very abundant they can cause considerable damage to plants (Ito \& Nagamine, 1981). Ecological studies of cicadas have focused on the life cycles of periodical cicadas (Williams \& Simon, 1995), sound communication (Sueur, 2002) and the control of pest species (Ito \& Nagamine, 1974, 1981). However, studies have rarely reported behavioural interactions between cicadas and other insects, with the exception of the hunting of cicada-killer wasps (Evans, 1966) and parasitization by sarcophagid flies, which locate cicadas acoustically (Soper et al., 1976).

A black, large-bodied (45-65 $\mathrm{mm}$ in body length) cicada, Cryptotympana facialis (Walker), occurs abundantly in urban areas of warm-temperate Japan and is considered a pest due to the noise it generates (Shiyake, 1999). Recently, I observed in urban parks in central Japan ants and flower chafers sucking exudates from holes drilled by these cicadas. This paper presents subsequent observations on the behavioural interactions between cicadas and other insects, in particular those feeding on tree sap.

\section{STUDY SITE AND METHODS}

Field studies of behavioural interactions between cicadas and other insects were carried out in two urban parks in Osaka City, in warm-temperate central Japan: Shotenyama Park $\left(34^{\circ} 38^{\prime} \mathrm{N}\right.$, $135^{\circ} 30^{\prime} \mathrm{E} ; 10 \mathrm{~m}$ a.s.1.) and Nagai Park $\left(34^{\circ} 36^{\prime} \mathrm{N}, 135^{\circ} 31^{\prime} \mathrm{E}\right.$; $7 \mathrm{~m}$ a.s.1.). Cryptotympana facialis adults usually emerge during
July-August. Another cicada species, Graptopsaltria nigrofuscata (Motschulsky), is also present in these parks in July-August, but it is much less abundant than C. facialis. The two parks were planted primarily with keyaki trees, Zelkova serrata (Thunberg) Makino (Ulmaceae) and C. facialis regularly sucks sap from their trunks and branches in late July.

The behaviour of $C$. facialis and other insects was observed on randomly selected keyaki trees for $1 \mathrm{~h}$ between 13:00 and 17:00 on both sunny and cloudy days during 2006: July 30 and August 12-15, 19, and 20. Cryptotympana facialis were most abundant on August 12 in Shotenyama Park and on August 13 in Nagai Park; on these dates, binoculars were used to count the cicadas, flower chafers and other insects on keyaki tree trunks and branches $0-8 \mathrm{~m}$ above the ground in order to determine the numerical relationships between them. Although two flower chafer species were observed, they were not determined to species because they are difficult to identify from a distance. The ants on each trunk were counted $0-150 \mathrm{~cm}$ above the ground. Thirteen trees in Shotenyama Park and 22 in Nagai Park were inspected. The trees in Shotenyama Park had an average diameter at breast height (130 $\mathrm{cm}$ above the ground) of $27.3 \pm$ $1.8 \mathrm{~cm}$, while trees in Nagai Park averaged $26.7 \pm 1.6 \mathrm{~cm}$ (mean $\pm \mathrm{SE}$ ). Pearson's correlation was used to analyse the relationships between the number of cicadas and other insects. The number of individuals was logarithmically transformed prior to analysis.

To determine the sequence of arrival of ants, flower chafers and other insects to feed on the sap exuding from the holes drilled by cicadas, the cicadas that had settled and were feeding on trunks were disturbed and caused to flee. The sites at which they had been feeding were observed for $10 \mathrm{~min}$. This field experiment was conducted between 13:50 and 16:15 on August 14 and 15 in Shotenyama Park ( $\mathrm{n}=5$ for $C$. facialis and $\mathrm{n}=1$ for G. nigrofuscata) and on August 14 in Nagai Park ( $\mathrm{n}=2$ for C. facialis).

\section{RESULTS}

Cryptotympana facialis were abundant on keyaki trees in both parks; at peak emergence, there were on average $14.9 \pm 1.7$ $($ mean \pm SE) individuals per tree in Shotenyama Park and $7.3 \pm$ 1.3 individuals per tree in Nagai Park. Tree trunks were heavily 

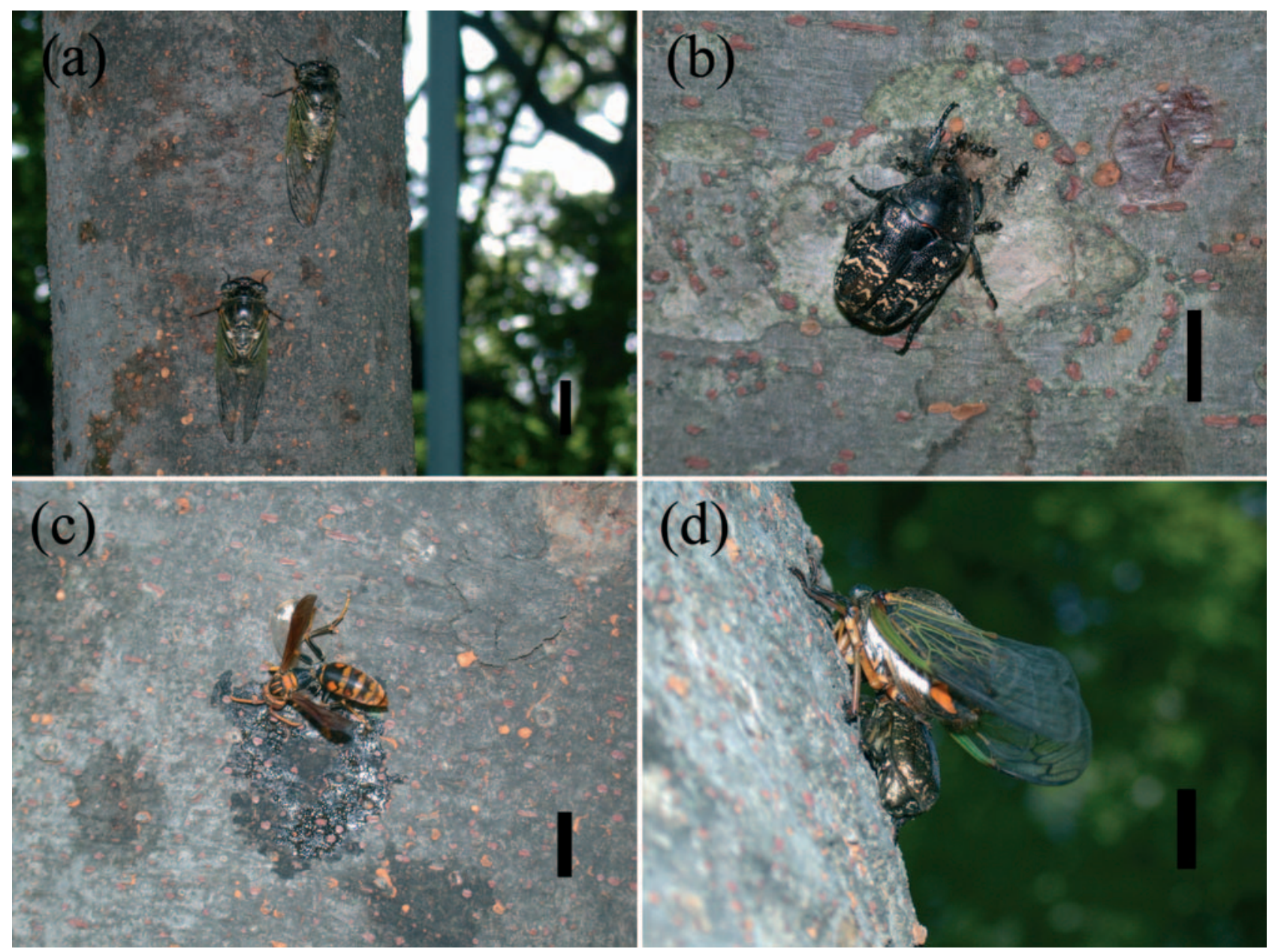

Fig. 1. (a) Cryptotympana facialis cicadas feeding on sap exuding from a Zelkova serrata trunk. (b) A flower chafer, Protaetia brevitarsis and Lasius japonicus ants feeding on sap exuding from a hole made by a cicada. (c) A vespid wasp, Polistes jokohamae, feeding on tree sap in a hole made by a cicada. (d) A flower chafer, P. brevitarsis, displacing a C. facialis feeding on tree sap. Scale lines: (a) $30 \mathrm{~mm}$, (b)-(d) $10 \mathrm{~mm}$.

stained with the exudates from holes drilled by the cicadas (Fig. 1a). Aggregations of three ant species, Formica japonica Motschulsky, Lasius japonicus Santschi and Crematogaster matsumurai Forel (Hymenoptera: Formicidae) fed on the exudates (Fig. 1b). Two wasp species, Polistes jokohamae Radoszkowski (Hymenoptera: Vespidae) (Fig. 1c) and Ampulex dissector (Thunberg) (Hymenoptera: Sphecidae), also fed on the sap. However, each tree had a maximum of only two to three of these wasps. In contrast, two flower chafers, Protaetia brevitarsis (Lewis) (Fig. 1b) and P. orientalis submarumorea (Burmeister) (Coleoptera: Scarabaeidae), were abundant and also sucked the sap. At peak cicada occurrence, there were in Shotenyama Park $47.9 \pm 8.7$ individuals of both chafer species per tree and in Nagai Park $5.7 \pm 1.4$ individuals per tree.

The number of flower chafers was positively correlated with numbers of $C$. facialis in Nagai Park $(\mathrm{R}=0.728, \mathrm{P}<0.0001, \mathrm{n}=$ 22) but not in Shotenyama Park $(R=0.418, P=0.159, n=13)$, while the number of ants was not correlated with numbers of $C$. facialis in either park $(\mathrm{R}=0.491, \mathrm{P}=0.0896, \mathrm{n}=13$ at Shotenyama Park; $\mathrm{R}=-0.071, \mathrm{P}=0.7554, \mathrm{n}=22$ at Nagai Park).

Three cases of flower chafers displacing feeding cicadas were observed, in which a flower chafer approached a feeding $C$. facialis, crept under the cicada's body and pushed it away (Fig. 1d). At first, the cicada withstood the chafer's assault, keeping its claws firmly attached to the bark. However, eventually the cicada gave up, moved a short distance away and used its stylets to pierce the tree and resumed feeding on sap. A droplet of tree sap appeared at the original hole and the flower chafer began feeding.

During field experiments, droplets of sap appeared within 30 $\mathrm{s}$ of removing feeding cicadas. The first insects to approach were ants, $F$. japonica and $L$. japonicus, which fed on sap in seven out of eight cases within 10 to 590 (average 170) s. Protaetia brevitarsis approached walking and fed on sap in two cases (one case: $G$. nigrofuscata) within 70 to $240 \mathrm{~s}$. In one case, $A$. dissector flew in and fed on sap within $300 \mathrm{~s}$.

\section{DISCUSSION}

Cicadas use their stylets to feed on xylem sap, which ants, wasps and flower chafers cannot directly access. Xylem sap is a dilute fluid containing water, amino acids and minerals (Chueng \& Marshall, 1973; White \& Strehl, 1978), and during hot summers, other insects may utilize the xylem sap exuding from cicada feeding sites as a source of water. Ants and wasps usually feed on flower nectar and aphid honeydew (Delabie, 2001), and flower chafers on fermented tree sap (phloem sap), ripe fruits and flower nectar (Yoshimoto et al., 2005; Yamazaki, pers. obs.). Their intake of xylem sap may compensate for a lack of some nutrients such as minerals. However, since the cicada's stylets pass through and damage phloem tissues on the 
way to the deeper xylem, a small amount of phloem sap may be present in the exuding sap.

The positive correlation between the numbers of cicadas and flower chafers per tree in Nagai Park suggests that trees with more cicadas exude more sap, thereby attracting more beetles. However, the number of ants was not correlated with the number of cicadas in either park, suggesting that ants forage for food sources other than exuding sap.

Ants and wasps fed on exuding sap, but were never observed to drive off cicadas. Therefore, ants and wasps have a commensal (cf. Begon et al., 1996) relationship with cicadas. Flower chafers certainly used feeding sites abandoned by cicadas, but were also observed displacing cicadas in order to feed on exuding sap. Thus, flower chafers can be considered both commensals and kleptoparasites (cf. Vollrath, 1984). Flower chafers exhibited similar aggressive tendencies when competing with other insects for fermenting tree sap (Yamazaki, pers. obs.)

Fabre (1879-1910) documents many ants, flower chafers, cerambycid beetles and other insects feeding on tree sap exuding from holes made by cicadas, Tibicen plebeja (Scopoli), in France, and stated that his observations did not support Aesop's tale of The Grasshopper and the Ant (derived from the original The Ant and the Cicada) because cicadas dig wells for ants and other insects and thus could not be considered lazy. Results from the present study support his assertion. In addition, van Noort (1995) reports that the lacewing Italochrysa neurodes (Rambur) is attracted to the calling and feeding cicada, Platypleura capensis (Linnaeus), and feeds on the sap exuding from holes made by the cicada during hot summers in South Africa Therefore, the interactions between cicadas and other insects reported here and in other studies may be common and widespread in hot seasons.

ACKNOWLEDGMENTS. I thank J. Yoshimoto of Kyoto University and S. Sugiura of Forestry and Forest Products Research Institute for their valuable advice on this study.

\section{REFERENCES}

Begon M., Harper J.L. \& Townsend C.R. 1996: Ecology, 3rd ed. Blackwell, Oxforrd, $1068 \mathrm{pp}$.

Chueng W.W.K. \& Marshall A.T. 1973: Water and ion regulation in cicadas in relation to xylem feeding. J. Insect Physiol. 19: $1801-1816$.

Delabie J.H.C. 2001: Trophobiosis between Formicidae and Hemiptera (Sternorrhyncha and Auchenorrhyncha): an overview. Neotrop. Entomol. 30: 501-516.

Dixon A.F.G. 2005: Insect Herbivore-Host Dynamics: Tree Dwelling Aphids. Cambridge Univ. Press, Cambridge, MA, 208 pp.
Evans H.E. 1966: The Comparative Ethology and Evolution of the Sand Wasps. Harvard Univ. Press, Cambridge, MA, 526 pp.

FABRe J.H. 1879-1910: Souvenirs Entomologiques. Delagrave, Paris.

Ito Y. \& Nagamine M. 1974: Distribution of infestations of a sugarcane cicada, Mogannia iwasakii Matsumura (Hemiptera: Cicadidae) in Okinawa Island with a discussion on the cause of outbreak. Appl. Entomol. Zool. 9: 58-64.

Iтo Y. \& Nagamine M. 1981: Why a cicada, Mogannia minuta Matsumura, became a pest of sugarcane: an hypothesis based on the theory of "escape". Ecol. Entomol. 6: 273-283.

SHIYAKE S. 1999: How many Cryptotympana facialis individuals are there at Nagai Park? Nature Study 45(12): 9-10 [in Japanese].

Soper R.S., Shewell G.E. \& Tyrrell D. 1976: Colcondamyia auditrix nov. sp. (Diptera: Sarcophagidae), a parasite which is attracted by the mating song of its host, Okanagana rimosa (Homoptera: Cicadidae). Can. Entomol. 108: 61-68.

StADLER B. \& Dixon A.F.G. 2005: Ecology and evolution of aphid-ant interactions. Annu. Rev. Ecol. Evol. Syst. 36: $345-372$.

SuEUR J. 2002: Cicada acoustic communication: potential sound partitioning in a multispecies community from Mexico (Hemiptera: Cicadomorpha: Cicadidae). Biol. J. Linn. Soc. 75: 379-394.

TJallingII W.F. \& Hogen Esch T. 1993: Fine structure of aphid stylet routes in plant tissues in correlation with EPG signals. Physiol. Entomol. 18: 317-328.

VAN NOORT S. 1995: An association of Italochrysa neurodes (Rambur) (Neuroptera: Chrysopidae) with Platypleura capensis (Linnaeus) (Hemiptera: Cicadidae). Afr. Entomol. 3: 92-94.

VollRath F. 1984: Kleptobiotic interactions in invertebrates. In Barnard C.J. (ed.): Producers and Scroungers: Strategies of Exploitation and Parasitism. Croom Helm, London \& Sydney, pp. 61-94.

White J. \& Strehl C.E. 1978: Xylem feeding by periodical cicada nymphs on tree roots. Ecol. Entomol. 3: 323-327.

WiLliams K.S. \& Simon C. 1995: The ecology, behavior, and evolution of periodical cicadas. Annu. Rev. Entomol. 40: 269-295.

Yoshimoto J., Kakutani T. \& Nishida T. 2005: Influence of resource abundance on the structure of the insect community attracted to fermented tree sap. Ecol. Res. 20: 405-414.

Received September 9, 2006; revised and accepted November 27, 2006 